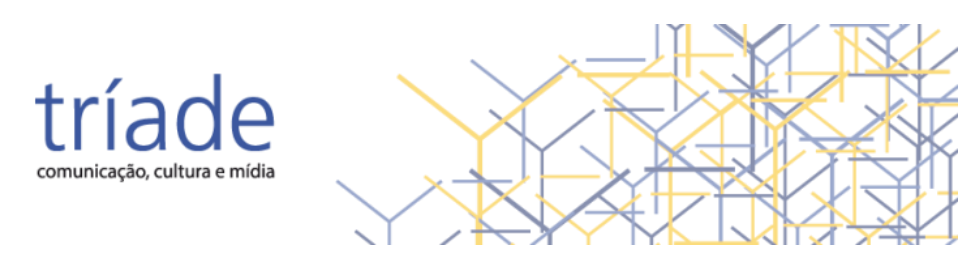

\title{
Cartografía de fronteras digitales
}

\author{
Cartografia das fronteiras digitais \\ Cartography of digital borders

\begin{abstract}
Rosario Radakovich - Universidad de la República | Montevideo | Montevideo | Uruguay I rosario.radakovich@fic.edu.uy | (D) https://orcid.org/0000-0002-1280-0916.
\end{abstract}

Resumen: Las fronteras constituyen la clave de las nuevas identidades nómades, identidades en las que los sujetos se anclan a múltiples puertos de significación vital. Si se plantean las fronteras internas al mundo digital en el que los jóvenes habitan su cotidianeidad, podemos observar una serie de espacios comunes que podrían catalogarse como de "integración", espacios que son percibidos como "normales", "habituales", "comunes", es decir, operan como territorios comunes y transversales socialmente como Instagram, Whatsapp y Youtube. Otros territorios digitales aparecen como espacios de diferenciación, en el que se tejen intereses, prácticas también distintas $y$ en los que a su vez se replican islas de diferenciación interna. Tal es el caso de Netflix, Twitter, Spotify y emblemáticamente de Finsta dentro de Instagram. Este artículo plantea resultados de la investigación "Identidades de consumo. Imaginarios y estilos de vida cultural", de corte cualitativa, basada en seis focus groups realizados a jóvenes y adultos, varones y mujeres de sectores sociales medios altos $y$ populares en Montevideo entre 2018 y 2019.

Palabras clave: Plataformas. Audiovisual. Representaciones.

Resumo: As fronteiras constituem a chave para as novas identidades nômades, identidades nas quais os sujeitos são ancorados em múltiplos portos de importância vital. Se forem consideradas as fronteiras internas do mundo digital em que os sujeitos habitam o seu quotidiano, podemos observar uma série de espaços comuns que podem ser classificados como "integração", espaços que são percebidos como "normais", "habituais", "comuns", ou seja, operam como territórios comuns e socialmente transversais como Instagram, WhatsApp e YouTube. Outros territórios digitais aparecem como espaços de diferenciação, nos quais interesses, também diferentes práticas se tecem e nos quais ilhas de diferenciação interna são, por sua vez, replicadas. É o caso do Netflix, Twitter, Spotify e, emblematicamente, do Finsta no Instagram. Este artigo apresenta os resultados da pesquisa "Identidades de Consumo. Imaginários e estilos de vida culturais", de natureza qualitativa, a partir de seis grupos focais realizados com jovens e adultos, homens e mulheres da classe média alta e popular em Montevidéu, entre 2018 e 2019.

Palavras-chave: Plataformas. Audiovisual. Representação. 


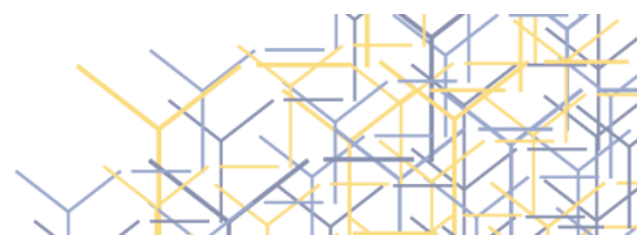

Abstract: Borders constitute the key to new nomadic identities, identities in which subjects are anchored to multiple ports of vital significance. If the internal borders of the digital world in which people inhabit their daily lives are considered, we can observe a series of common spaces that could be classified as "integration", spaces that are perceived as "normal", "habitual", "common", that is, they operate as common and socially transversal territories such as Instagram, WhatsApp and YouTube. Other digital territories appear as spaces of differentiation, in which interests, also different practices are woven and in which islands of internal differentiation are in turn replicated. Such is the case of Netflix, Twitter, Spotify and, emblematically of Finsta within Instagram. This article presents the results of the research "Consumer Identities. Imaginaries and cultural lifestyles", of a qualitative nature, based on six focus groups held with young people and adults, men and women from upper middle and popular social sectors in Montevideo between 2018 and 2019.

Keywords: Platforms. Audiovisual. Representation. 


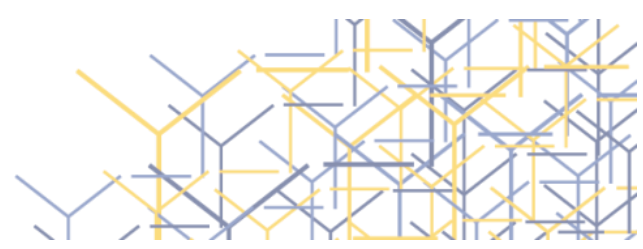

\section{Introducción}

¿Utilizan las redes? E6: Internet, Facebook, en la tele también. E: Por Twitter [risas]. E1: Yo creo que hoy en día todo el mundo usa mucho lo que son las redes sociales, ¿no? como que es algo que ya está incluido en uno, como que uno está con el celular y siempre está entrando a Facebook, Whatsapp, Instagram, es lo que más se usa. (Grupo Jóvenes Mujeres NSE B Sacude, información verbal $\left.{ }^{1}\right)$.

Las nuevas tecnologías de información y comunicación irrumpen en la cotidianeidad transformando sustantivamente las prácticas culturales, escindidas de las coordenadas tradicionales de tiempos, espacios y dinámicas presenciales de uso del tiempo libre. La presencia física se torna prescindible para la comunicación cotidiana, mientras la presencia digital es omnipresente. Así, la comunicación interpersonal mediatizada se configura como una nueva forma de presencia-la virtual o digital - que representa un continuo ininterrumpido, un vínculo aparentemente tan sólido como la presencia misma (GUREVICH, 2018). En otras palabras, la ausencia física se desvanece en beneficio de una presencia virtual que coloniza la cotidianeidad y el uso del tiempo (RADAKOVICH; WORTMAN, 2019; GAYO et al., 2020).

Este cambio implica transformaciones radicales en nuestras formas de percepción del tiempo libre, los espacios y prácticas vinculadas al consumo cultural y a la comunicación e incluso implica una nueva forma de identidad cultural y expresión de sí mismo, sobre todo para los más jóvenes. La tecnología adquiere por ello una altura existencial. En las nuevas formas de la presencia, aquellas virtuales y digitales propias de las nuevas tecnologías (TIC'S), apenas un teléfono celular alcanza para el acceso. Teléfono que, como señala Allard (2017) permite un mestizaje de

${ }^{1}$ Entrevista con seis focus groups realizados a jóvenes y adultos, varones y mujeres de sectores sociales medios altos y populares en Montevideo entre 2018 y 2019. 
signos (escriturales, sonoros, icónicos y de datos) así como la conjunción de lenguajes alfabéticos, ideográficos e informáticos.

De ahí que en este nuevo "sensorium" (BENJAMIN, 1982), resulta central pensar las experiencias y las "mediaciones" (MARTÍN-BARBERO, 2002) como el modo de acceder a las nuevas TIC'S. Es precisamente internet la columna vertebral de las nuevas tecnologías (BONDER, 2008), el espacio en donde los jóvenes, de manera cada vez más aguda (BARRANTES; BENÍTEZ, 2016), fundan sus identidades y consumen incontables horas (ESCALONA; VILLA, 2015). Para ellos, el esfuerzo de ser único, auténtico, verdadero, lo que se denomina como el individualismo expresivo (GALLAND; ROUDET, 2012) hoy se despliega a partir de internet en las redes sociales con la experimentación, intercambio y búsqueda de entretenimiento.

Como señala Octobre (2019), en las redes se trata, sobre todo, de inventar, descubrir, compartir lo que se es o lo que se quiere ser. Internet conjuga tanto el acceso a contenidos culturales y a modalidades de personalización para la puesta en escena de sí mismos como les da herramientas de creatividad y expresión que lo transforman en el dispositivo paradigmático de sociabilidad, intercambio y colaboración. Cristaliza entonces el ideal de destacarse de los otros también, como característica humana de realización a partir de la búsqueda de mecanismos que resalten sus cualidades, aptitudes, propiedades o realizaciones (ELIAS, 1994).

En el nuevo escenario de la vida cotidiana este artículo se propone dar cuenta de los nuevos territorios, fronteras, bordes, márgenes que

(U) delinean la cartografía de la vida digital en la que habitan los jóvenes en Montevideo actualmente. Cartografía de vivencias, procesos, agendas. Algunos previsibles, otros inesperados, algunos globales, otros situados e intersticiales; algunos generales y generalizables, otros emergentes, particulares, singulares.

Una cartografía de usos sociales, tácticas culturales y mediaciones 
tecnológicas que admite territorios tangibles e intangibles, presenciales y virtuales. Territorios que registran fronteras que son todo menos un nonplace (AUGÉ, 1992) por su relevancia simbólica y por su poder para dar cuenta de las asimetrías sociales. Bordes que conforman espacios ambiguos que unen y dividen al mismo tiempo (MARISCO; TATEO, 2017), y que son a la vez permeables o porosos. De esta forma, consideramos estos territorios como relacionales, y por lo tanto sumamente dinámicos.

Una primera frontera que surge para los consumos culturales de los jóvenes se define entre los territorios tangibles e intangibles, las salidas en circuitos culturales definidos territorialmente en el marco de la ciudad, del barrio y aquellas prácticas que se inscriben en el universo digital, virtual de la red. Sobre todo, porque durante años el anclaje urbano fue significante para los jóvenes: la salida a la vereda, al murito de la esquina, el atravesar la ciudad. Hoy se equiparán las travesías urbanas a las virtuales, donde el acto de transgresión resulta de quebrar las asimetrías de los algoritmos y los sesgos que ofrecen las plataformas.

En segundo lugar, las fronteras internas del mundo digital en el que los jóvenes habitan su cotidianeidad, revelan una serie de espacios comunes que podrían catalogarse como de "integración", espacios que son percibidos como "normales", "habituales", "comunes", es decir, operan como territorios comunes y transversales socialmente como Instagram, Whatsapp y Youtube. Otros territorios digitales aparecen como espacios de diferenciación, en el que se tejen tácticas y prácticas también distintivas (BOURDIEU, 1979) y en los que a su vez se inscriben "islas" de diferenciación interna. Tal es el caso de Netflix, Twitter, Spotify y

(U) emblemáticamente de Finsta dentro de Instagram.

Este artículo plantea resultados de la investigación titulada "Identidades de consumo. Imaginario y estilo de vida cultural de los uruguayos", en la Faculty of Information and Communication, Universidad en Montevideo, Uruguay (2018-2021), ejecutada a partir de técnicas cualitativas de aproximación a partir de la realización entrevistas a 


\section{tríade}

intermediarios culturales y seis focus groups realizados a jóvenes y adultos, varones y mujeres de sectores sociales medios altos y bajos en Montevideo en 2019.

\section{Metodología}

Como se señaló en la introducción previa, este artículo surge como parte de la investigación "Identidades de consumo. Imaginarios y estilos de vida de los uruguayos" emplazada en la Facultad de Información y Comunicación de la Universidad de la República y financiado por la Agencia Nacional de Investigación e Innovación de Uruguay. La investigación se desarrolló a partir de 2018 y adoptó un modelo metodológico cualitativo para el análisis de las transformaciones recientes en las identidades de consumo cultural (BORGERSON, 2005), localizadas en el Uruguay contemporáneo.

Dichos cambios se inscriben en la transición de un imaginario tradicional, el mesocrático, que configura el estilo de vida cultural de buena parte del siglo 20 en Uruguay, hacia otros imaginarios marcados por la globalización y por el giro expresionista (TAYLOR, 1991), que conduce a los sujetos a buscar la 'originalidad' en sus prácticas cotidianas. Asociado a este impulso identitario cobra creciente importancia la noción de 'autenticidad' como un ideal moderno de consumo (GRAYSON; MARTINEC, 2004) y de vida.

Un tema central del proyecto fue el estudio de las identidades y del "sí mismo" (self) en relación a las prácticas de consumo actuales. Así se

(U) retomó un estudio clásico sobre "el sí mismo extendido" (BELK, 1988; ROCHBERG-HALTON, 1989) a sus posesiones y al consumo. Además de localizar el estudio en el Uruguay contemporáneo, procuramos avanzar en la caracterización del problema del punto de vista epistemológico, pues definimos las 'identidades' en tanto resultantes socio-históricas, localizadas del 'sí mismo', siendo éste concebido como un proceso 
reflexivo continuo de auto-interpretación (COLAPIETRO, 1989; GIDDENS, 1991; ANDACHT; MICHEL, 2005, 2015, 2016). Desde este abordaje semiótico de la identidad humana, adherimos a la propuesta de que "Somos capaces de dar razones del comportamiento en el que estamos embarcados" (GIDDENS, 1991).

Las identidades de consumo se analizaron a través de diversas dimensiones de aproximación: orientaciones estéticas (gustos), disposiciones y prácticas (rutinas y rituales), mecanismos de integración en el consumo cultural (aspiraciones, expectativas, tácticas, estrategias, metas), éticas de consumo (valores, normas), explorando tanto los mecanismos de cohesión y consensos, cuanto las tensiones y conflictos que surjan de representaciones que aparezcan "legítimas" o "hegemónicas" de un nosotros cultural frente a diversos subgrupos 0 subculturas emergentes y estilos de vida cultural.

Cabe destacar que los jóvenes que fueron partícipes del estudio que se educaron en el ámbito público - primaria y secundaria - han sido parte de la experiencia del Plan Ceibal que supone una computadora por niño para la incorporación de competencias audiovisuales. Se presume que esta peculiaridad también ha permitido afianzar sus destrezas digitales.

El diseño de investigación se centró en dos técnicas cualitativas de investigación aplicadas consecutivamente: 20 entrevistas en profundidad semi-estructuradas aplicadas a intermediarios culturales (BOURDIEU, 1979; FEATHERSTONE, 2000) y seis Grupos Motivacionales, o Focus Group (MORGAN, 1997). Este artículo explora resultados de investigación específicos resultantes de la aplicación de Focus Group cuyo objetivo fue

<U explorar en profundidad razones y debates que subyacen en las opciones de consumo en el uso del tiempo libre, explorando limitantes, estrategias, éticas y valores de consumo, así como orientaciones estéticas y representaciones sociales controversiales.

Como criterios de muestreo no probabilístico para conformar los seis grupos motivacionales se exploraron situaciones que comportan 


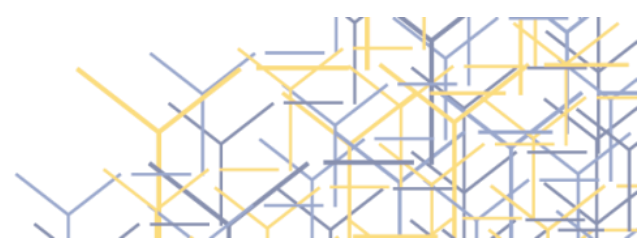

oposiciones relevantes en términos de género, perfiles educativos y ocupacionales en posiciones socioeconómicas polarizadas. Se realizó un total de seis grupos focales compuestos por ocho personas, de los cuales cuatro se realizaron en la Facultad de Información y Comunicación (FICUdelar), y dos grupos efectuados en el centro cultural y deportivo Sacude en Casavalle, barrio en la periferia de Montevideo.

El material que surge de estos focus group da cuenta de relatos de su vida cotidiana, narrativas pobladas de diversas identidades, que nos permiten acceder y comprender de modo empírico y teórico a la vez cómo funciona su imaginación y su creatividad en cuanto al empleo de todo aquello que en la cultura que los rodea y que los conforma, todo aquello de interés para el desarrollo de sus inclinaciones, de su expresivismo identitario.

\section{Análisis}

E7: Para mí también, el cambio que más se ve es la tecnología. Por ejemplo, hoy en día sin tecnología, sin internet, digamos, como que una persona no puede vivir. [...] Y antes no nos importaba eso, vivíamos el día a día. Hoy está todo enroscado en la tecnología, y como que se dejó un poco de lado el ser uno mismo y no guiarse tanto por eso. No sé, la generación de ahora es tecnología, tecnología, tecnología. (Grupo Mujeres Jóvenes, NSE A).

La cartografía de los consumos culturales "a-tecnológicos" y "presenciales" es percibida secundaria a la digital en los relatos de los

(U) jóvenes entrevistados, sobre todo aquellos de nivel socioeconómico medio-alto. Importa más en donde estoy y qué reacción tengo a una selfie, a los comentarios de amigos, si se viralizó algún contenido propio o de los referentes - youtubers, instagramers, influencers en general que sigo - que dar atravesar la ciudad o permanecer en casa. ¿Cuáles serían las búsquedas de los momentos "a-tecnológicos"? Los jóvenes que 
formaron parte del estudio reconocen tiempos y espacios a-tecnológicos vinculados al hacer deporte, dormir, estudiar, pero sobre todo cuando se trata de aquellas actividades dedicadas al "estar" en familia y al uso del espacio público abierto como ir a parques, salir a la rambla con amigos. Los lazos fuertes, presenciales, cotidianos, parte de la trayectoria biográfica siguen siendo relevantes. Aun así, la mediación tecnológica se revela naturalizada y los amigos virtuales se incluyen en las relaciones interpersonales.

E5: En mi tiempo libre tomamos mate, charlamos. Hago video llamadas con mis padres, por lo general. También estoy en las redes sociales. (Grupo Jóvenes Mujeres, NSE A).

El uso tecnológico se solapa a todo momento de vida. Se relata tan integrado como desapercibido y supeditado de un registro digital y si no, como señala una joven participante del estudio, no existe. Existe entonces si está en las redes sociales. Y de acuerdo a los entrevistados revela la realidad, permite conocer al otro. No parece asumirse el juego de máscaras que la presencia virtual implica.

Claro, (Instagram) es algo que usás como para mostrarte al mundo, y también para ver en qué anda el otro. Las historias: la gente vive subiendo cosas de lo que está haciendo en ese momento. Y si alguien no subió una historia es como que no está haciendo eso. (Grupo Jóvenes Mujeres NSE A).

E1: [...] si yo te sigo a vos puedo saber todo lo que vos hacés, todo lo que subís. MJ: ¿sólo en YouTube? L: No. Instagram, Facebook, todo internet, una cosa lleva a la otra. MJ: ¿pero que usan más?: Instagram, Instagram. F: ¿Que miran en Instagram? ¿Qué cosas les interesa? E: Chusmear. L: Podes mirar el perfil de personalidad. (Grupo Jóvenes Varones NSE B 
Sacude).

Para los jóvenes que participaron del estudio y que viven en contexto de precariedad - aquellos entrevistados en el Centro Cultural Sacude de Casavalle -, las referencias presenciales del uso del tiempo libre se hacen más nítidas, se desarrollan con mayor detalle, aunque estén todo el día conectados también a las redes sociales. Como relataba una de las entrevistadas del Sacude, nada más tangible que "la sangre" para revelar una vivencia presencial. La fuerza de la violencia del entorno les recluye en el entorno próximo, pero el territorio y la presencia física sigue siendo una dimensión relevante de la vida.

E1: Nosotras, no sé si fue contigo o fuimos con Sofía y Dylan, que estábamos parados en una barra y de repente vemos un tipo chorrear sangre, en Mumbai fue. Y corría para todos lados el loco con un vaso todo roto y una botella de pico y le abrió la cabeza adentro del baile. $Y$ nosotros no sabíamos qué hacer, entonces ahí dije "no, acá aflojo la salida" porque no. (Grupo Jóvenes Mujeres NSE B Sacude).

Quizás por la relevancia que tiene transitar la ciudad desde una zona marginalizada y lejana de la periferia. Ir a McDonalds, a Montevideo Shopping, al Barrio Sur a participar de una cuerda de tambores o comparsa, ir a comer hamburguesas a lo "del Rulo" o a hacer deporte al mismo centro en el que fueron entrevistados, el Sacude, constituyen referencias de integración social y de status que delatan las fronteras de la marginalidad y los prejuicios que aparecen.

Yo soy Paula, tengo 18 y vengo acá a jugar al fútbol y ta. E1: Bueno yo soy Adriana tengo 22 años y cuando tengo tiempo libre que es casi todo el tiempo [risas] vengo al SACUDE $y$ hago candombe $y$ hago animación... E4: Bueno, yo me llamo Sofía y tengo 18 años y ta vengo acá al SACUDE en mis tiempos libres. Vengo a hacer actividades, hago fútbol, baile, bueno, 
todo lo que puede haber acá y ta. (Grupo Mujeres, NSE B Sacude).

Como se adelantó previamente, ello no quiere decir que este grupo se vea excluido de los territorios digitales, porque como manifiestan, utilizan todo el tiempo las redes.

E1: Digamos que yo de las 24 horas diarias, 23 estoy en las redes, es tremendo. KB: ¿Cómo? E1: Que yo de las 24 horas diarias, 23 estoy en las redes, porque dormito, me despierto, miro el celular y me vuelvo a dormir. Así estoy todo el día. KB: ¿Qué es lo que solés mirar ahí? E1: Whatsapp, mucho Whatsapp e Instagram más que nada. Facebook no, en Facebook comparto memes todo el día, pongo "compartir", "compartir", "compartir" [risas]. (Jóvenes Mujeres. NSE B, Sacude).

Si se plantean las fronteras internas al mundo digital en el que las jóvenes habitan su cotidianeidad, podemos observar una serie de espacios comunes que podrían catalogarse como de "integración", espacios que son percibidos como "normales", "habituales", "comunes", es decir, operan como territorios comunes y transversales socialmente como Instagram, Whatsapp y Youtube. Ante la falta de contacto físico, o ante su postergación en lo que hace a su significación, las redes operan como mecanismo de conexión social.

Se trata de una conexión social que se expresa de diferente manera que la conexión y sociabilidad física. La lógica de las redes de afinidad basadas en "compartir" contenidos - imágenes, chistes o memes, textos e

<U ideas -, la dinámica de otorgar a otros "likes" y de "seguir" a un "amigo" virtual da cuenta del apoyo mutuo, de reforzar al otro (otrx). También expresa un juego de máscaras de reconocimiento mutuo. 


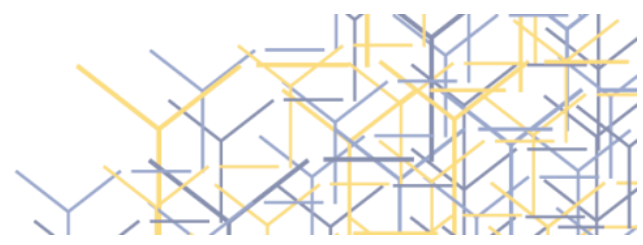

Cuadro I - Territorios de prácticas y representaciones de lo digital

\begin{tabular}{ll}
\multicolumn{1}{c}{$\begin{array}{c}\text { Diferenciación } \\
\text { (isla simbólica de diferenciación) }\end{array}$} & $\begin{array}{c}\text { Integración } \\
\text { (patrón de normalidad, territorio } \\
\text { compartido) }\end{array}$ \\
Setflix & Instagram \\
Twitter & Youtube \\
& Whatsapp
\end{tabular}

Fuente: Elaboración propia.

Como advierte Donnat (2013), esta modalidad binaria de gusto/disgusto ha trivializado la exposición pública de juicios de apertura y cierre sobre el grupo de amigos y quienes no forman parte de la comunidad de afinidad. Por esta razón quizás es que surgen territorios digitales de delimitación, bordes de relieve, mecanismos de diferenciación en los que se tejen tácticas de distanciamiento social, "islas" o espacios concéntricos de diferenciación interna y endogamia. Tal es el caso emblematicamente de Finsta dentro de Instagram.

Finsta es la síntesis del término fake Instagram, que significa un espacio recóndito, fuera de la mirada pública. Revela una última frontera digital: la privatización de la imagen pública de las redes sociales.

Cuando se trata de abordar la intimidad digital, el pasaje de Instagram a "Finsta" (Finstagram) es significativo. Opera como una competencia digital "distintiva" también, como un club endogámico, de cierre de exposición virtual y se hace presente entre las jóvenes de sectores altos.

E1: Sí. Pero también hay... ahora es como que se creó una moda de hacerse un Finsta [Finstagram]. ¿No sé si saben lo que es? - ¿Hacerse qué? E1: Un Finsta, es tipo un Instagram solo para los amigos donde subís, tipo, cosas... fotos que no subirías a algo que tenés expuesto a todo el mundo, sino que contás más de tu 


\section{tríade}

vida y de tus intimidades, y yo qué sé, de tu día a día. - ¿Es nuevo eso que decís? E1: Sí, claro, es más personal. $\mathrm{Y}$ es enfocado a tu grupo de... tu entorno. E2: Es más privado. E1: Ahí va. E2: Yo justo tengo Instagram y tengo Finsta. Pero igual mi Instagram está privado, o sea, no lo puede ver todo el mundo. Mi Instagram que uso para el círculo pero un círculo más cercano. Y después tengo el Finsta que sí, creo que tengo a veinte personas como mucho. $Y$ ese sí lo uso para mis amigos, mis hermanos, para subir cosas que, claro, no subiría a mi otro Instagram porque, ta', son cosas que no me gusta que las vean todos los otros seguidores, sino para la gente más de cerca. (Grupo NSE A).

El uso social de las redes revela la centralidad de la imagen sobre el relato y un profundo hedonismo que con las selfies se ven protagonistas. El número de valoraciones "Me gusta" se traducen en popularidad, legitimidad, éxito social. Se trata de la necesidad de reconocimiento, reputación y autoestima.

Yo creo que si te dejás permear mucho por el Instagram, estás muy pendiente del qué dirán, del cómo te ves, capaz. Vas a estar muy pendiente de charlar con alguien y no podés estar solo. También esas cosas: estar todo el tiempo con gente, o estar todo el tiempo hablando con alguien. (Grupo Mujeres Jóvenes NSE A).

$Y$ yo que sé, hay gente que tiene Instagram para los amigos. Yo me hice hace poco igual pero por lo que veo es eso, como más conocidos, de acá. Hay gente, yo qué sé, en Estados Unidos... o una persona $X$ sube fotos para tener seguidores, para tener gente que vea más hashtags, no sé qué. (Grupo Mujeres Jóvenes NSE A).

El status social se centra entonces en el componente emotivo de nuestras apropiaciones culturales a partir de los likes y emoticones. Las emociones se aplican a productos culturales de muy diversa índole. El gusto se intensifica en su dimensión subjetiva, emocional, en una suerte 
de consumo emotivo, un consumo "de experiencias" que se exhibe como trofeo cuando implica una suerte de "seguidores" importante, casi como un "ratting" de la vida cotidiana. Para aquellos jóvenes de sectores populares -del pueblo-, no tener "popularidad" es un estigma social.

¿Y en Instagram a quiénes siguen? E1: A nosotras nos seguimos. E: Pah, re triste [risas]. E1: Nos seguimos nosotras. (E1, E, Grupo NSE B).

Para estos jóvenes no aparece la necesidad explícita de reducir el universo de exposición a partir de la creación de un "Finstagram". De hecho, es interesante la frustración de apenas "seguirse a sí mismas" como revelan las chicas que participaron del grupo focal de zonas populares - Casavalle. Apenas "los del barrio", "la familia en el Interior del país" son quienes "les siguen" en Instagram.

De allí que surge la intensidad de los referentes, de los influencers y celebrities en sus redes. Los referentes son personas y personajes populares vinculados sobre todo al fútbol, a la música, en particular aquellos que vienen de la plena y la cumbia, también del rap y el trap, y figuras del ámbito de la estética para aquellas que se vinculan al maquillaje por ejemplo como relatan las jóvenes a continuación.

MJ: ¿Pero no siguen a algún influencer, a alguna persona? E: Sí, Messi, Cristiano Ronaldo, todos los jugadores de fútbol. E3: A algún conocido, algún famoso. Y si no a los del barrio, pero no a todos [...]. KB: ¿Y qué famosos seguís? E1: La música, a ella le gusta mucho la música, iah negrita! MJ: ¿Cuáles son los que vos más seguís? E3: Ah, no, los de acá, no sé, los que cantan plena, reggeaton. E1: Marcos Da Costa [risas]. E1: El Gucci. E3: Sí, no sé, después por bandas. E1: La Sandonga. Ya la conozco yo, como no habla está bien. E3: Después sigo la banda de mis primos también y ta. MC: ¿Qué banda? E3: Los Saborizados. MC: ¿Son primos tuyos? E3: Sí. E1: Familiar de "el beicon" [risas]. KB: ¿Qué hacen? ¿Hacen 
toques? E3: Tocan plena. E2: Yo en el Instagram sigo también, similar a ellas. También sigo maquillajes, cosas así, para aprender y eso. E2: Sí, son de acá, la mayoría familiares, amigos. Y después cantantes. KB: ¿Esas se dedican al maquillaje? E2: No, esas son otras cuentas. KB: Y los específicamente de maquillaje, que te enseñan cómo maquillarte y todo, ¿son uruguayos? E2: No, son de otros países. KB: ¿De Argentina puede ser? E2: Sí. MJ: ¿Cómo vos llegás hasta ellos? E2: Porque cuando ponés en el buscador ahí te aparecen algunos, entonces yo entro y ahí empiezo a seguir a los que me gustan. MJ: ¿Y vos? [...] Después mucho Instagram como que no.... Me pierdo, soy más del Facebook, más de publicar memes todo el día [risas]. (Grupo Mujeres Jóvenes NSE B Sacude).

E5: Ay, es lo mismo que hacen todas. Sigo a personas de acá que conozco, después jugadores de fútbol algunos y cosas de baile que me gustan. E5: A Luis Suárez, Cavani, a esos que son de Uruguay. Nada más. E6: Y bueno, yo hago lo mismo así que... [risas]. No sé, más cantantes. KB: ¿Qué otros cantantes? E6: Noriel, todos de trap así que... Cosas de baile y maquillaje también. MC: ¿Quiénes son las personas conocidas del trap acá en Uruguay? E6: No tengo ni idea, yo sólo sigo a Noriel así que ta. MC: Y el Duki por ejemplo en Argentina.... E6: Ah, sí, pero no me gusta tanto. MJ: ¿Acá quién es que vos dijiste? ¿Qué nombre vos dijiste? E6: Noriel. MJ ¿Noriel se llama? E6: Sí. Y ta. E4: Lo que dijeron ellas más tipo páginas graciosas. KB: Memes. E4: No, ¿viste que hay cuentas en Youtube graciosas en videos? Bueno, yo sigo a esas en Instagram. MJ: Ah, claro, las personas que tienen como un canal de Youtube, vos las seguís en el Instagram. (Grupo Mujeres Jóvenes NSE B Sacude).

Entre celebrities, influencers y youtubers se pueden delimitar algunas diferencias. Entre las celebrities figuran los íconos del fútbol mundial, sobre todo los uruguayos Luis Suarez y Edinson Cavani que son referencia y modelo de rol para estos jóvenes. Entre los influencers, definidos como "personas comunes" que se destacan en el ámbito digital, son recomendadores privilegiados, activos en redes sociales, relevantes 
para las marcas no solo por la cantidad de seguidores sino por la calidad de relacionamiento con ellos. Ellos ofrecen su cercanía, su credibilidad, presencia y espontaneidad (GUREVICH, 2018, p. 153).

A su vez los youtubers son productores y gestores de contenido audiovisual que usan YouTube como su plataforma de comunicación. Youtube se menciona recurrentemente entre los jóvenes como espacio de distensión para acceder a vídeos humorísticos, así como para escuchar música en vez de Spotify por su carácter "pago" y como tutorial laboral o para mejorar destrezas personales.

Como señala Igarza (2009) los jóvenes van hacia las plataformas que distribuyen contenido ilegal cuando la propuesta es mejor y más fácil de usar, es multiventana y no tienen las engorrosas barreras de una modalidad de pago demodé e inadaptada a sus modalidades de consumo digital abierto, gratuito, inmediato.

Está claro además que los jóvenes han incorporado las prácticas transmedia (SCOLARI, 2018) a partir de una combinación de lenguajes, medios y plataformas que implican sinergias y articulación entre medios para el logro de producciones integradas. El alfabetismo transmedia se considera como un conjunto de habilidades, prácticas, valores, sensibilidades y estrategias de aprendizaje e intercambio desarrolladas y aplicadas en el contexto de una nueva cultura colaborativa (SCOLARI, 2018), a partir de videojuegos, redes sociales y prácticas de creación e intercambio de contenidos.

El territorio digital de Spotify en el grupo de mujeres jóvenes de Casavalle es un poco menos nítido. Disputado por Youtube más (U) establecido, más "abierto" y claramente gratuito - aunque Spotify también tenga su versión gratis -, se destaca por el uso generalizado. Integrado en las habilidades del uso cotidiano a partir del acceso al "historial" para recuperar la trayectoria sonora de preferencias. Las nuevas preferencias surgen a partir de las sugerencias de la red. 


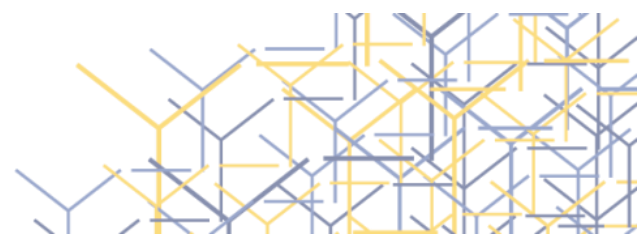

MC: ¿Dónde escuchan música en el celular? ¿En Youtube? E: Sí. E6: En Spotify. E1: Yo iba a decir eso, en Spotify. E6: Yo no lo tengo, pero lo escuché por ahí. E6: No, ella escucha Spotify. E1: Yo escucho Spotify porque ahora me quedé sin computadora, hasta que no me la traigan y tipo tengo que bajar música y es un huevo. E6: Yo tengo que escuchar por Youtube porque ta, no tengo Spotify. E4: Yo tengo la tarjeta. E6: Si no, la descargás en la página y la tenés en tu teléfono. E4: Claro, te queda en el teléfono. MJ: ¿Vos cargás una tarjeta en el celu? E4: Yo tengo la tarjeta, tengo música y tengo las fotos. E6: Mastercard y todas esas cosas ahí también. E1: Qué boluda. MJ: ¿Vos también? E: Sí, yo sí. MJ: ¿Escuchás por Youtube? E: Sí. MC: ¿Escuchás cualquier canción? ¿Dejás que corra Youtube? E: Sí porque ya me queda el historial ahí, ya aprieto el historial y te queda todo lo que yo escuché. (Grupo Mujeres Jóvenes, NSE B Sacude).

E1: Para mí el problema con Spotify... Hay un plan familiar, entonces podés pagar, no sé, te hacen un descuento por cinco usuarios, y mi padre, después de un año de decirle que lo compre, lo compró, por suerte [E4 se ríe]. Pasa eso cuando lo tenés gratis es más difícil de usar porque no lo podés usar en todos lados, a no ser que tengas datos. Es más difícil. A mí me pasaba al principio, me resultaba difícil de usar, me costó entenderlo pero es buenísimo porque tiene radios, tiene listas o playlist de lo que sea, de música de los $80^{\prime}$, de cualquier cosa. Y capaz que sí el rango uruguayo no es muy amplio pero, ponele, yo soy de pasarme de facetas de música de rock en español, rock en inglés, country, de todo. E6: Yo utilizo Youtube porque Spotify probé la versión gratis y no me parece. Te pasa saltando anuncios. Nunca lo pagué entonces la verdad para mí... Igual ahora también, Youtube está con todo. (Grupo Mujeres Jóvenes NSE A).

Entre los varones del Sacude aparece "Youtube" de una forma más intensa y generalizada vinculado al uso de "tutoriales". Tutoriales que también surgen en el caso de las jóvenes mujeres aplicado a la incorporación de competencias en la estética, en maquillaje, peluquería y otros oficios e intereses. Podría asociarse esta forma de conocimiento 
incorporado por los jóvenes, sobre todo aquellos de menores recursos socioeconómicos como parte del movimiento "maker culture". La denominada "cultura del maker/fabricante", supone que el aprendizaje deviene de la construcción de conocimiento "al hacer algo" que se puede compartir. Este aprender haciendo borronea los límites entre el aprendizaje formal e informal (HALVERSON; SHERIDAN, 2014, p. 498).

F: ¿Ven mucho los tutoriales? J: Yo sí, todo lo que tenga que ver con estudio si. Entro a youtube solo por estudio. Sino cuando quiero aprender alguna jugada nueva para practicar cuando estoy aburrido. F: ¿Jugada de qué? J: De cualquier deporte, soy híper competitivo. F: ¿Y hay mucho tutorial de eso? J: Si, tipo yo soy de ir a jugadas que generalmente nadie las hace, me gusta ir a lo extremo. (Grupo Varones Jóvenes NSE B Sacude).

En primer lugar, la fabricación como un conjunto de actividades. En segundo lugar, los espacios de fabricación y creación como comunidades de práctica, con entornos de aprendizaje diseñados y centrados alrededor de una práctica, no en las herramientas sino en el proceso y potencialmente en el producto. En tercer lugar, la instancia maker como momentos de desarrollo identitario, donde el maker/creador/fabricante (se) va forjando a través del hacer y así estaría también forjando no solo objetos materiales, físicos, creativos, sino su propia identidad como sujeto.

Otros defienden fervorosamente y opinan que el verdadero poder de esta revolución son sus efectos democratizadores, y que ahora, casi

(I) cualquiera puede innovar, y que casi cualquiera puede hacer. "Ahora, con las herramientas disponibles en un espacio de fabricante, cualquiera puede cambiar el mundo" (HATCH apud HALVERSON; SHERIDAN, 2014, p. 10). De acuerdo con Allard e Vandenberghe (2003) una revolución de la "fabricación personal" supone la re materialización de lo digital y también la digitalización del mundo físico, lo que denomina como "contrahacer". 


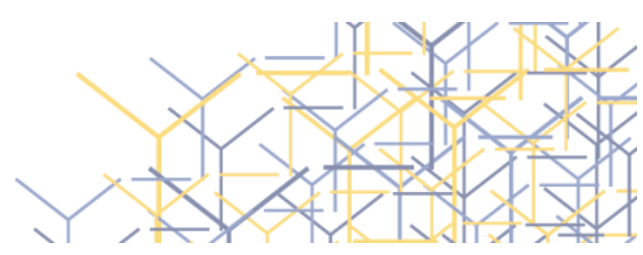

En las herramientas digitales, Google aparece como el motor de búsqueda destacado. Sobre todo, porque se visualiza como un habilitador a contenidos culturales. Lo que en el relato además se percibe de forma crítica. La advertencia del tránsito radical a la vida cultural digital, que cambia inmediatez y acceso enciclopédico a cambio de centralizar las prácticas culturales, revela que estos jóvenes son conscientes de las implicancias y críticos.

M: En Google buscas la película que te gusta y la miras. $\mathrm{N}$ : Claro por ejemplo estuviste una semana jodida y te perdiste los 5 capítulos de la novela, entra a youtube y encontrás la novela entera. No te perdes nada. E: La tecnología tiene sus pro y sus contras no. L: Esa tecnología apago la tele, el diario. iPara qué vas a pagar comprando un diario! si lo buscás y lo ves. $\mathrm{Pa}$ leer, leo un libro, de algo que me gusta, algo puntual. G: Hoy entrá a Google y ya te aparece todo el libro. Ponele el texto que haces un curso, entras a internet $y$ en una hora te enseña casi todo en un tutorial. (Grupo Varones Jóvenes NSE B Sacude).

Para el intercambio de información se contraponen Facebook y Whatsapp que es la red generalizada y Twitter que aparece como un espacio "cheto", designado así por los jóvenes del Sacude. Mientras Facebook se percibe como espacio de "memes" y como un espacio colonizado por la familia y las generaciones mayores. Facebook es considerado demodé, porque es el territorio digital de padres y abuelos. Es el territorio digital de la familia.

Whatsapp permite intercambiar opiniones y mensajes entre grupos

<U de amigos. Se considera un espacio transversal, democrático de comunicación entre pares, sobre todo, pero también con la familia. Muy diferente es el caso de Twitter que se percibe como un espacio de opinión distante, que exige además conocimiento y un alto nivel de exposición pública. Constituye un espacio distintivo (BOURDIEU, 1979), posicional y jerárquico, basado más en conocimientos que en emociones. 
Por otro lado, plataformas como Netflix han logrado flexibilizar las condiciones de acceso a la programación de contenidos audiovisuales, sobre todo series y películas - aunque también documentales y docu series. No obstante, los jóvenes tienden a acceder a partir de Google a cualquier plataforma que les proporcione la posibilidad de visionado sin pagar - sea Youtube u otra.

La característica que destacan los jóvenes de Netflix es la personalización de la oferta, pues consideran son ellos quienes eligen dónde, cómo, qué ver y cuándo verlo. En esta "aparente" libertad los jóvenes se involucran en prácticas como el denominado "binge watching" o maratones de episodios.

No obstante, esta mayor autonomía supone sólo a medias un mayor control en la elección de contenidos sino el estar sujetos a la aplicación de mecanismos sofisticados de inteligencia artificial para la inducción a los contenidos. La reflexión y conocimiento de la forma como opera la plataforma y los sesgos de los algoritmos es explícito entre las jóvenes de mayor nivel socioeconómico.

Tengo entendido que geográficamente sí está restringido: acá en Uruguay no te ponen el mismo rango de películas, documentales, etc., que en Brasil, Argentina, etc. Pero sí sé que es una selección... pero en mi caso me aparecen las cosas que yo guardo para ver más tarde, las cosas que me recomiendan ellos según la película que vi ayer, y después todo el rango: drama, terror, etc. (Grupo Mujeres Jóvenes NSE A).

De hecho, su identidad global, su espíritu de "ciudadano del mundo" se ve amedrentado por una oferta audiovisual aún situada y condicionada por criterios geográficos tradicionales: Netflix ofrece una programación diferente de acuerdo al continente y región en la que cada uno se inscriba. Parte del sentido de crítica y las tácticas de protesta entonces se dedican a cómo hackear el algoritmo que les une a su identidad geográfica, el 


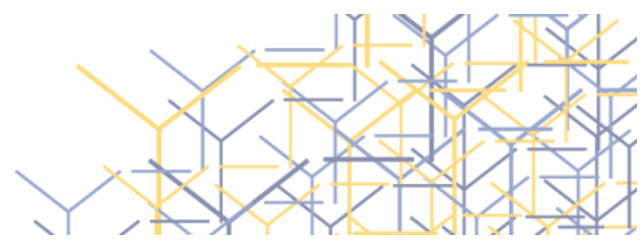

lugar y la nación en la que se inscriben.

Como señala Octobre (2019), la movilidad cultural - real o virtual se está convirtiendo en un nuevo criterio de clasificación o de dominio entre los que denomina "móviles \& inmóviles" donde se destaca la diferencia entre aquellos que tienen recursos para manipular códigos, referencias y varios registros sociales y tecnológicos quienes no. Estas referencias pueden aplicarse a modalidades gradacionales que caracterizan a jóvenes de perfil diferenciado en relación a las redes y a su experiencia tecnológica en el uso del tiempo libre: pasivos \& activos, aquellos que se adaptan y aquellos que subvierten el orden, pro status quo \& críticos, revolucionarios, etc.

\section{Consideraciones finales}

Este artículo se propuso explorar la relevancia de la vida digital para los jóvenes en su consumo cultural y uso del tiempo libre. La elaboración de un "no lugar" (AUGÉ, 1992) como el digital para el uso del tiempo libre invita a su cartografía. Una cartografía no estática sino dinámica, viva, subjetiva y particular en la que se revela los usos sociales de las TIC'S de los jóvenes entrevistados, aunque probablemente extendidos entre los jóvenes a nivel más general.

El análisis de los relatos hace evidente que la tecnología es un bien cultural en sí mismo para ellos. Constituye un nuevo consumo cultural y a la vez modifica la relación con los otros bienes culturales. La relación con la música, el cine, entre otras expresiones cambia sustantivamente al

<U hacerse cada vez más plenamente digital.

De hecho, la primera frontera que atraviesan los jóvenes en el uso del tiempo libre es el proceso de inversión de jerarquía entre lo presencial y lo virtual. Esto parece afirmarse sobre todo en aquellos jóvenes de nivel socioeconómico alto. No obstante, todos tienen una vida presencial en el que la sociabilidad de pares es importante y para todas las redes sociales 
son parte permanente de sus espacios y tiempos de ocio.

El mapa de preferencias, rutinas y sentidos otorgados a las redes y plataformas digitales da cuenta de usos de conexión, integración y otros mecanismos de diferenciación, distinción e individualización de los gustos culturales en las nuevas generaciones. Algunos emergentes como el uso del Finsta, parece ir a contracorriente de la utilidad más generalizada de las redes sociales. Justamente, no hay un uso único ni un acatamiento de manual de las empresas tecnológicas. La tecnología se humaniza y con ello sus usos son oblicuos no lineales ni absolutamente predecibles. Burlar el algoritmo o generarse espacios privados e íntimos en espacios públicos como las redes sociales e incluso incorporar competencias digitales de aprendizaje de destrezas artísticas como relata uno de los jóvenes del Sacude respecto a su incursión en el trap, todos estos ejemplos no hacen sino reafirmar la existencia de tácticas y mediaciones de sentido, y advierten los márgenes de autonomía y creatividad que los jóvenes tienen respecto a las tecnologías y las cartografías más previsibles.

El carácter poroso de estas nuevas fronteras se reconoce en la 'irrupción' de las TIC'S a partir del uso cotidiano de las redes sociales. No se trata de una rutina sino de una irrupción de mensajes, avisos, fotos, timbres sin fin que se interponen en la vida cotidiana dando cuenta de un uso social itinerante, desanclado y portátil. Ello implica un despliegue permanente, aunque extremadamente fragmentado y fugaz de diversos trazos de identidad cultural volcados a distintos ámbitos digitales.

Un consumo cultural que logra incidir en la agenda biográfica (temas, tiempos, personas, lugares) de las personas, ofreciendo nuevas

(I) rutas al debate colectivo y agendas sociales, aunque colocando al individuo en primera línea de exhibición de sus percepciones, opiniones, imágenes e imaginarios colectivos. 


\section{tríade}

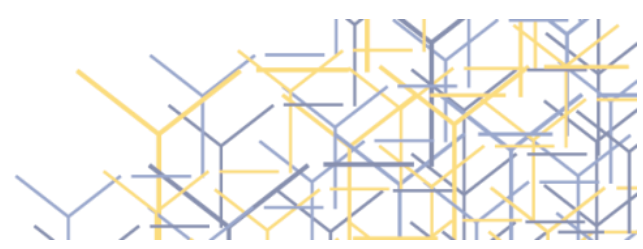

\section{Referencias}

ALLARD, L. Partages créatifs: stylisation de soi et appsperimentation artistique. Communication \& Langages, Paris, v. 194, n. 4, p. 29-39, 2017.

ALLARD, L.; VANDENBERGHE, F. Express yourself! Les pages perso. Entre légitimation techno politique de I'individualisme expressif et authenticité réflexive peer to peer. Réseaux, Paris, v. 117, n. 1, p. 191-219, 2003.

ANDACHT, F.; MICHEL, M. Passos para uma convergência de duas teorias dialógicas do self. Psicologia, São Paulo, v. 27, n. 2, p. 70-80, 2016.

ANDACHT, F.; MICHEL, M. Towards a convergence of Dialogical Self Theory and Semiotic Self Theory through triadic phenomenology. Theory and Psychology, Toronto, v. 25, n. 6, p. 814-832, 2015.

ANDACHT, F.; MICHEL, M. A semiotic reflection on Self-Interpretation and Identity. Theory and Psychology, Toronto, v. 15, n. 1), p. 51-75, 2005.

AUGÉ, M. Los "no lugares". Espacios de anonimato. Barcelona: Gedisa, 1992.

BARRANTES, C. R.; BENÍTEZ, L. S. TIC e inclusión social: un estudio cualitativo de las trayectorias de apropiación de internet para el estudio, el trabajo y la gobernanza en Buenos Aires. In: COMMUNICATION POLICY RESEARCH CONFERENCE, 2016, México. Anais [...]. México: in conjunction with CLT2016, 2016. Disponível em:

https://papers.ssrn.com/sol3/papers.cfm?abstract id=2852940. Acesso em: 13 nov. 2020.

BELK, R. W. Possessions and the Extended Self. Journal of Consumer Research, Toronto, v. 15, n. 2, p. 68-139, 1988.

BENJAMIN, W. Discursos interrumpidos. Taurus, Madrid, v. 1, 1982.

BONDER, G. juventud, género \& tic: imaginarios en la construcción de la sociedad de la información en américa latina. Arbor, Madrid, CLXXXIV 733, p. 917-934, sep./oct. 2008.

BORGERSON, J. Materiality, Agency, and the Constitution of Consuming Subjects: Insights For Consumer Research. Advances in Consumer Research, San Antonio, v. 32, p. 439-443, 2005.

BOURDIEU, P. La distinction: Critique sociale du jugement. Paris: Éditions de Minuit, 1979. 


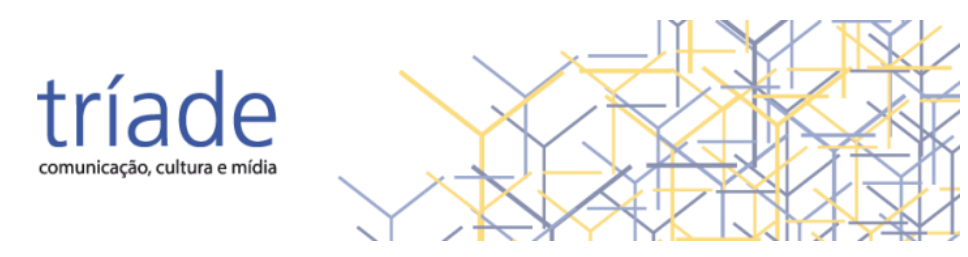

COLAPIETRO, V. Peirce's approach to the self. Albany: SUNY Press, 1989.

DONNAT, O. Les connaissances artistiques des Français. Eléments de comparaison, 1988-2008. Culture Études, Paris, v. 5, n. 5, 2013.

ELIAS, N. La teoría del símbolo. Barcelona: Península, 1994.

ESCALONA, Y. P. ; VILLA, W. M. C. Jóvenes en la encrucijada de los nuevos tiempos. Una mirada a sus prácticas y consumos culturales desde la Universidad de Granma. Revista Científica Guillermo de Ockham, CaliColombia, v. 13, n. 1, p. 127-134, 2015.

FEATHERSTONE, M. Cultura de consumo y posmodernismo, Madrid: Amorrortu, 2000.

GAYO, M. [et al.]. Consumos culturales en el Sur Latinoamericano. Santiago: UDP, 2020.

GALLAND, O. ROUDET, B. Une jeunesse différente? Les valeurs des jeunes Français depuis 30 ans. Paris: INJEP/Le documentation française, 2012.

GIDDENS, A. Modernity and Self-Identity. Self and Society in the Late Modern Age. Stanford: Stanford University Press. 1991.

GRAYSON, K. ; MARTINEC, R. Consumer Perceptions of Iconicity and Indexicality and Their Influence on Assessments of Authentic Market Offerings. Journal Of Consumer Research, Toronto, v. 31, p. 296-312, 2004.

GUREVICH, A. La vida digital. Intersubjetividad en tiempos de plataformas sociales. Buenos Aires: La Crujía, 2018.

HALVERSON, E. R.; SHERIDAN, K. The Maker Movement in Education. Harvard Educational Review, Cambridge, v. 84, n. 4, p. 495-504, 2014.

IGARZA, R. Burbujas de ocio. Nuevas formas de consumo cultural. Buenos Aires: ICRJ, 2009.

MARISCO, G.; TATEO, L. B. Tensegrity and Development in Dialogue. Integr Psych Behav, New York, v. 51, p. 536-556, 2017.

MARTÍN-BARBERO, J. Oficio de cartógrafo. Travesías latinoamericanas de la comunicación en la cultura. Santiago: FCE, 2002. 


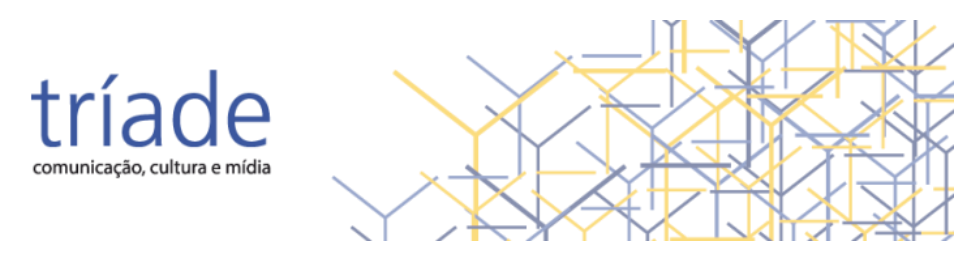

MORGAN, D. Focus Groups as Qualitative Research. Thousand Oaks. California: Sage, 1997.

OCTOBRE, S. ¿Quién teme a las culturas juveniles? Las culturas juveniles en la era digital. México: Océano Travesía, 2019.

RADAKOVICH, R.; WORTMAN, A. (Coord.). Mutaciones del consumo cultural en el siglo XXI. Buenos Aires: Teseo ALAS CLACSO, 2019.

ROCHERBERG-HALTON, E. Meaning and Modernity. Social Theory in the Pragmatic Attitude. Chicago: The University of Chicago Press, 1989.

SCOLARI, C. A. Adolescentes, medios de comunicación y culturas colaborativas. Aprovechando las competencias transmedia de los jóvenes en el aula. Barcelona: H2020 transliteracy Project, 2018.

TAYLOR, C. The ethics of Authenticity. Cambridge: Harvard University Press, 1991.

\section{Sobre a autora:}

Rosario Radakovich - Doctora en Sociología (UNICAMP, Brasil) con Diplomas de Posgrado en Comunicación Audiovisual (UAB, España), en Estudios Internacionales (UDELAR) y Licenciatura en Sociología (UDELAR). Profesora Adjunta de la Facultad de Información y Comunicación (FIC) de la Universidad de la República (UDELAR, Uruguay). Investigadora Nivel I de la Agencia Nacional de Investigación e Innovación (ANII). Realizó pasantías de investigación posdoctoral en Sorbonne Nouvelle Paris III en la Cátedra Unesco "Savoir-devenir à l'ère du développement numérique durable" (2018 y 2019). Co-Coordinadora del Proyecto "Identidades de consumo" financiado por la Agencia Nacional de Investigación e Innovación (ANII 2019-2021). Especializada en consumo cultural, medios audiovisuales y digitales, políticas de comunicación y cultura. Publicó los libros "Retrato cultural. Montevideo entre cumbias, tambores y óperas" (2011) y "Territorios televisivos" (2003) de autoría propia, coordinó los libros "Mutaciones del consumo cultural en el siglo XXI" (RADAKOVICH; 1U WORTMAN, 2019), "El cine nacional de la década. Industrias creativas innovadoras" (RADAKOVICH et al., 2014) y el informe nacional "Trazando un mapa de los medios digitales en Uruguay" (RADAKOVICH et al., 2014). Participó en co-autoría en el "Primer, Segundo y Tercer Informe de Imaginarios y Consumo Cultural" (ACHUGAR et al., 2002, DOMINZAÍN et al., 2009 y 2015) entre otros. Fue representante latinoamericana de la Association for Cultural Studies (ACS, 2010-2016) y participa activamente del GT 03 de la Asociación Latinoamericana de Sociología. 